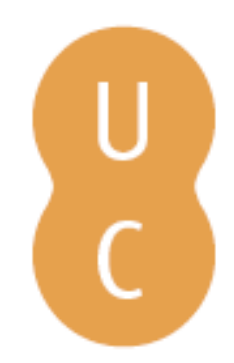

\title{
nombalina
}

\section{Cartografia Municipal de risco com recurso ao Model Builder}

\author{
Autor(es): Rocha, José \\ Publicado por: Imprensa da Universidade de Coimbra; RISCOS - Associação
}

URL

persistente: URI:http://hdl.handle.net/10316.2/34816

DOI: $\quad$ DOI:http://dx.doi.org/10.14195/978-989-96253-3-4_25

Accessed : $\quad$ 26-Apr-2023 14:48:00

A navegação consulta e descarregamento dos títulos inseridos nas Bibliotecas Digitais UC Digitalis, UC Pombalina e UC Impactum, pressupõem a aceitação plena e sem reservas dos Termos e Condições de Uso destas Bibliotecas Digitais, disponíveis em https://digitalis.uc.pt/pt-pt/termos.

Conforme exposto nos referidos Termos e Condições de Uso, o descarregamento de títulos de acesso restrito requer uma licença válida de autorização devendo o utilizador aceder ao(s) documento(s) a partir de um endereço de IP da instituição detentora da supramencionada licença.

Ao utilizador é apenas permitido o descarregamento para uso pessoal, pelo que o emprego do(s) título(s) descarregado(s) para outro fim, designadamente comercial, carece de autorização do respetivo autor ou editor da obra.

Na medida em que todas as obras da UC Digitalis se encontram protegidas pelo Código do Direito de Autor e Direitos Conexos e demais legislação aplicável, toda a cópia, parcial ou total, deste documento, nos casos em que é legalmente admitida, deverá conter ou fazer-se acompanhar por este aviso.

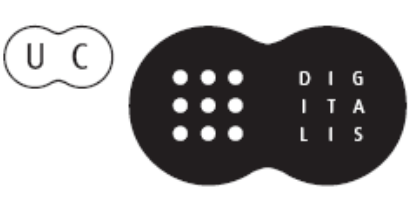



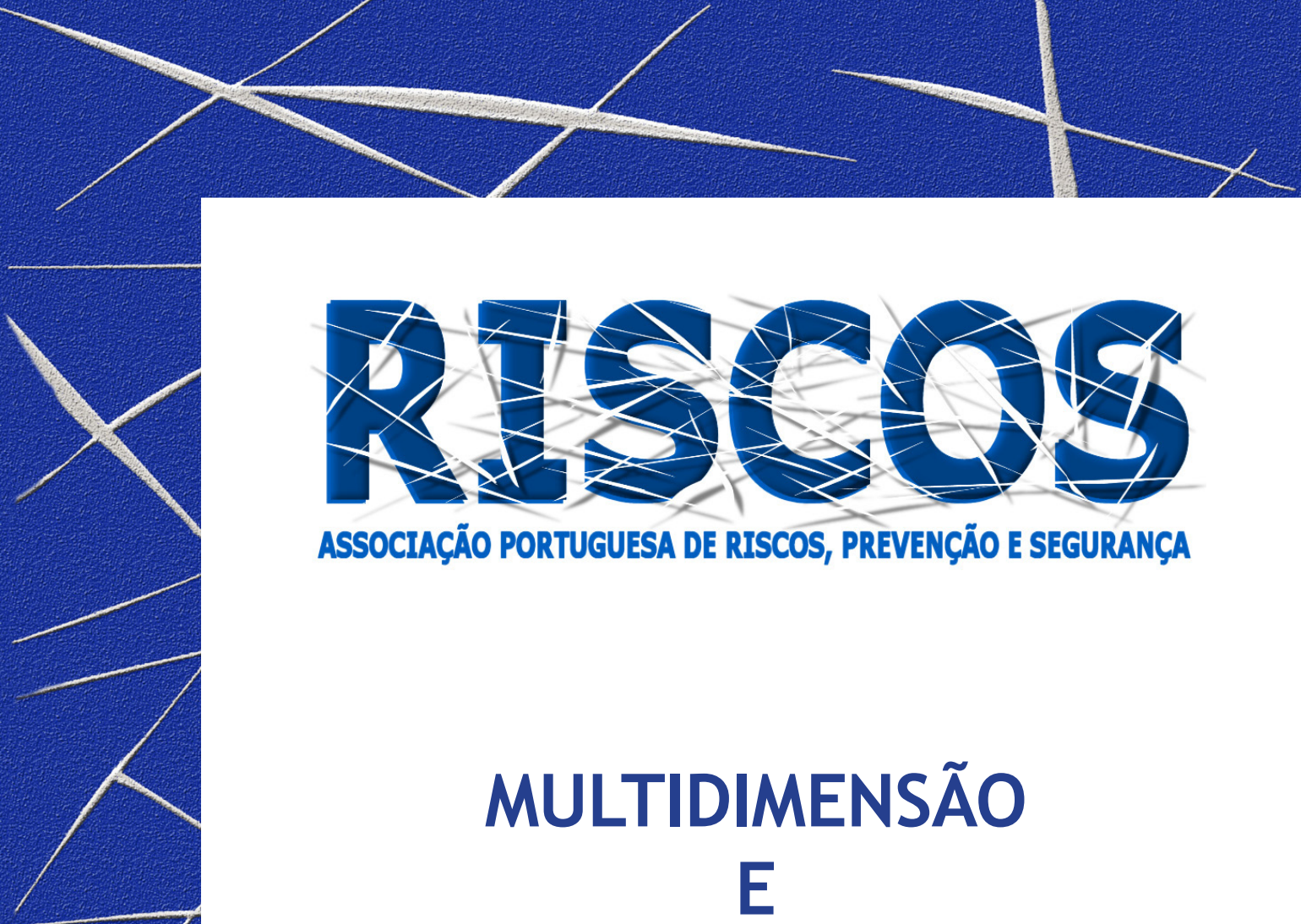

ASSOCIAÇÃO PORTUGUESA DE RISCOS, PREVENCCÃO E SEGURANÇA

MULTIDIMENSÃO

E
TERRITÓRIOS DE RISCO

III Congresso Internacional

I Simpósio Ibero-Americano

VIII Encontro Nacional de Riscos

Guimarães

2014 


\title{
CARTOGRAFIA MUNICIPAL DE RISCO COM RECURSO AO MODEL BUILDER
}

\author{
José Rocha \\ Departamento de Geografia, Instituto de Ciências Sociais da Universidade do Minho \\ jmanuelfrocha@sapo.pt
}

\begin{abstract}
RESUMO
A cartografia municipal de risco, mais concretamente a cartografia de risco de incêndio é um método de identificação, caracterização e avaliação da ocorrência de risco dendrocaustológico. Contudo, a utilização da cartografia de risco permite uma articulação crucial para o planeamento de emergência, que indica os locais potenciais de perigosidade e de risco de incêndio contribuindo assim para uma prevenção e vigilância antecipada dos locais mais susceptíveis.

A utilização dos SIG torna-se numa ferramenta potencializadora para compreender, quantificar, validar e prever a localização das entidades e o seu comportamento, tornando-se, por isso, instrumentos fundamental para o desenvolvimento de uma visão integradora do território como um todo, de forma a facilitar a intervenção em áreas menores (Costa, 2010).

Com base no Plano Municipal de Defesa da Floresta Contra Incêndios elaborou-se um Model Builder para a Cartografia de Risco com o intuito de facilitar o processo de produção cartográfico.
\end{abstract}

Palavras-chave: (Cartografia; PDMFCl; Model Builder;).

\section{Introdução}

«Os incêndios são considerados um fenómeno que ocorre globalmente (Bowman et al., 2009 e González-Pérez et al., 2004), havendo maior incidência no Sul da Europa (Portugal, Espanha, Grécia, Itália e França), EUA, Canadá, Chile e Austrália, tanto os países europeus como os restantes tem grande historial de investigação científica e gestão dos incêndios florestais, no entanto a incidência dos incêndios acompanha as mudanças globais do clima (Bento-Gonçalves et al., 2011)» (Rocha et. al., 2013).

0 processo de avaliação do risco de incêndio florestal assume-se como complexo devido a complexidade dos fenómenos que resultam dos incêndios florestais. Este processo é potencialmente causado pelo homem, no entanto, estão também ligados outros factores, que contribuem para a propensão do incêndio florestal, onde se engloba: coberto vegetal, relevo e o clima, bem como as variáveis sociais. A avaliação do risco de incêndio, normalmente é traduzida em índices com intuito de possibilitar a concretização dos elementos em mapas caracterizadores do risco (Antunes, 2011).

A cartografia municipal de risco, mais concretamente a cartografia de risco de incêndio é um método de identificação, caracterização e avaliação da ocorrência de risco dendrocaustológico. Contudo, a utilização da cartografia de risco permite uma articulação crucial para o planeamento de emergência, uma vez indica os locais potenciais de perigosidade e de risco de incêndio contribuindo assim para uma prevenção e vigilância antecipada dos locais mais susceptíveis. Assim sendo, com o recurso ao software ArcGIS 10.1 e com base no Plano Municipal de Defesa da Floresta Contra Incêndios elaborou-se um Model Builder para a Cartografia de Risco com o intuito de facilitar o processo de produção cartográfico. Com estudo de caso, o Município de Guimarães, procedeu-se ao tratamento dos dados referentes aos anos de ocorrência de incêndio e das áreas ardidas, disponibilizados pelo pelo Instituto de Conservação da Natureza e Floresta (ICNF). 


\section{A Metodologia}

Em Portugal, a metodologia adoptada para a elaboração da cartografia de risco de incêndio baseia-se no modelo da AFN (Figura I), que é constituído por quatro parâmetros: probabilidade, vulnerabilidade, susceptibilidade e risco de incêndio.

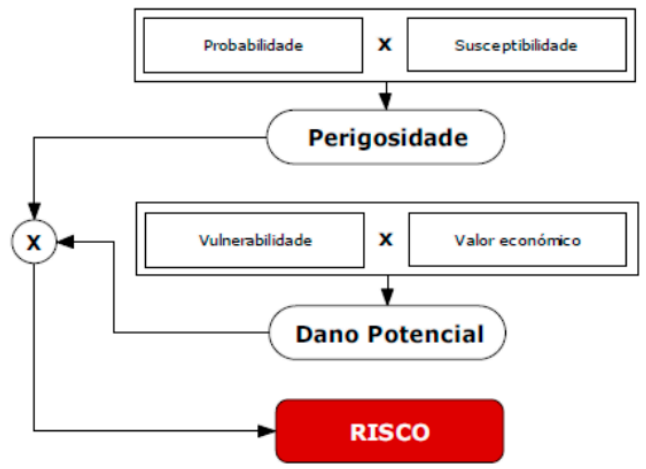

Figura I - Modelo de Risco

Fonte: http://www.osgeopt.pt/sites/default/files/files/Comunicacao_SASIG4_ PedroVenancio.pdf

\section{A utilização do Modelo em Model Buldier}

O surgimento dos SIG possibilita novos fluxos de trabalho e também a simplificação de diversos métodos e índices transformando-os numa referência espacial, como por exemplo num mapa. Contudo, torna-se morosa essa tarefa devido a diversidade de ferramentas que têm de ser utilizadas através do software, porém essa tarefa é diminuta quando é elaborado um modelo de trabalho (Model Builder).

Assim sendo, o Model Builder permite criar modelos (representação simplificada e gerenciável da realidade) a partir de fluxos que unem uma sequência de ferramentas necessariamente presentes no ArcToolbox e base de dados. O Model Builder permite tanto criar fluxos de rotina de trabalho quanto a criar novas ferramentas (Medeiros, 2014).

No fluxo de trabalho foram criados 4 modelos (Fig. II), ou seja, o modelo de probabilidade, modelo de susceptibilidade, modelo de perigosidade e o modelo de risco

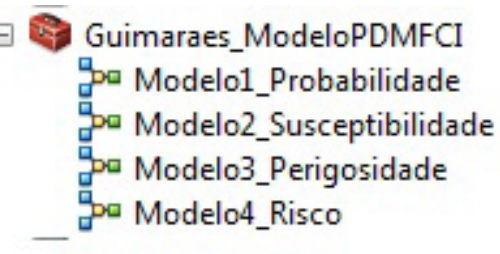

Figura II - Model Builder

Na construção do Modelo de Probabilidade (Fig. III) procede-se a individualização dos dados dos diferentes anos referentes às áreas ardidas, que incide desde 1990 até ao último ano disponibilizado pelo ICNF, no entanto no ao de 2004 não existem dados oficiais relativamente as áreas ardidas para o concelho de Guimarães. 
«Esta probabilidade anual determina-se, para cada pixel, dividindo:

$$
\frac{\Omega}{f .100}
$$

Em que $f$ é o número de ocorrências registadas, $\Omega$ o número de anos da série. (...), multiplica-se $f$ por 100 podendo usar apenas valores inteiros, ignorando a parte decimal. Reclassifique o seu raster de probabilidade de modo a que todas as áreas que arderam apenas uma vez sejam igualadas às que nunca arderam. (...) As áreas que nunca arderam devem ser reclassificadas de zero para um (...)» (Direcção da Unidade de Defesa da Floresta, 2012).

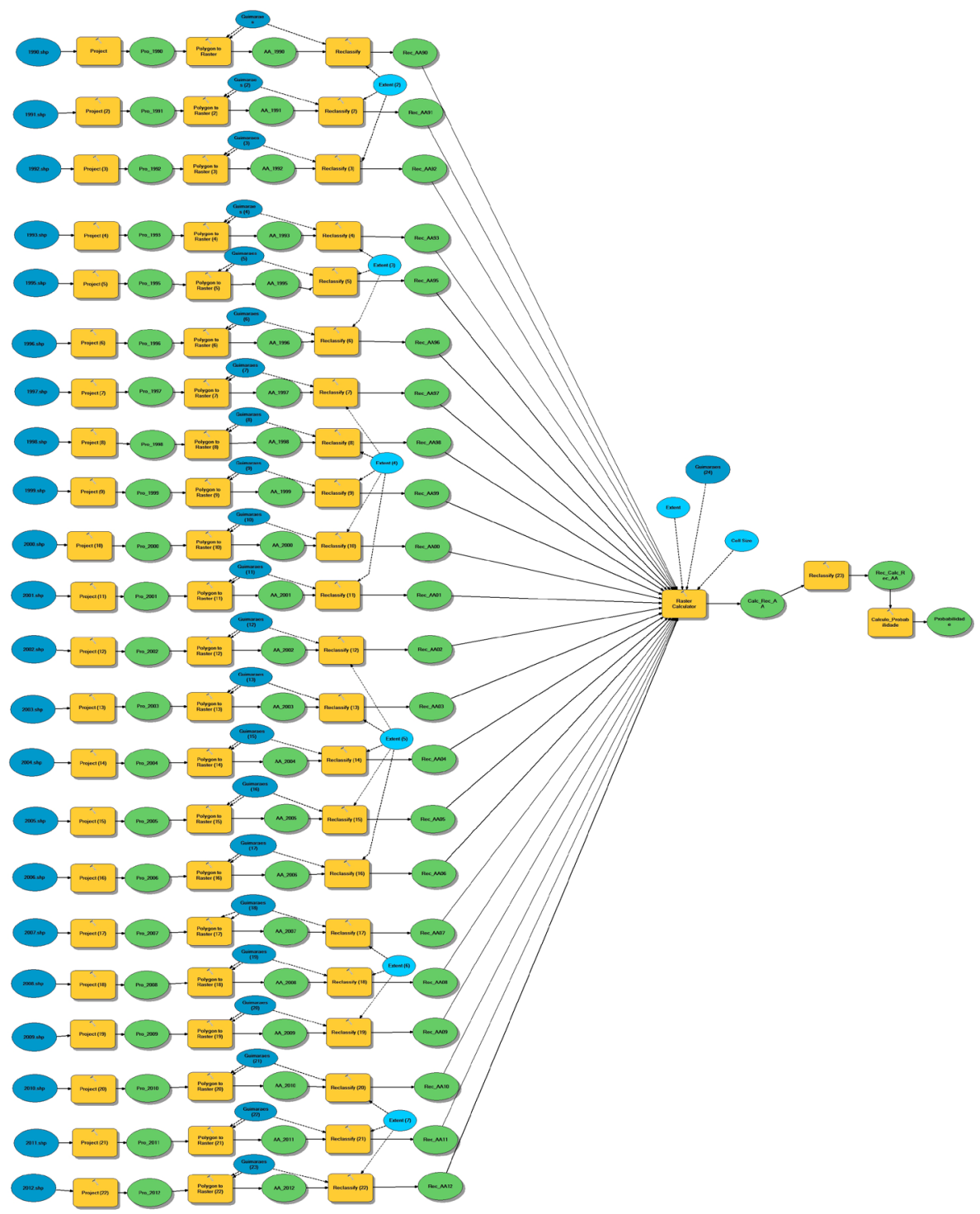

Figura III - Extrato do Modelo de Probabilidade 
A elaboração do Modelo de Susceptibilidade (Fig. IV) resulta da criação de um mapa de declives do concelho de Guimarães e da elaboração da Carta de Ocupação do Solo (COS).

Para a ocupação do solo é desejável a utilização de uma cobertura o mais actualizada possível. Os declives e a COS devem ser reclassificados, segundo as escalas e ponderações do Guia Técnico de PDMFCI.

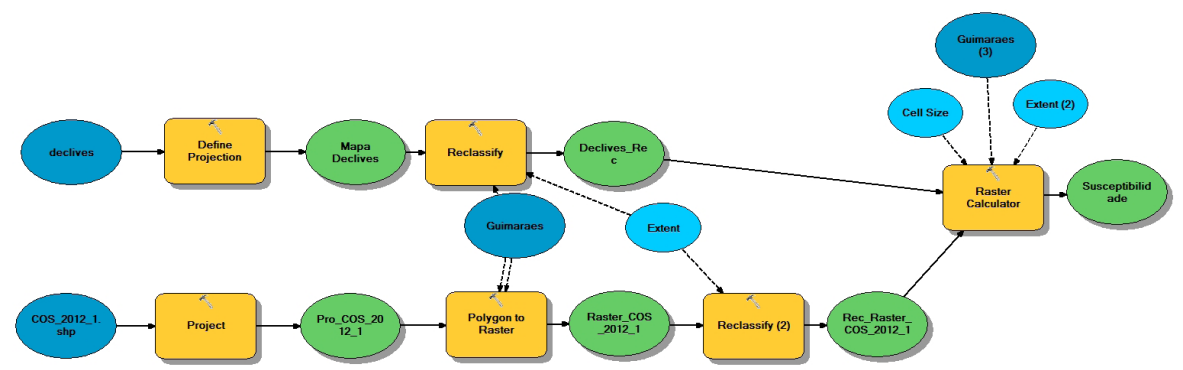

Figura IV - Modelação esquemática em Model Builder do Modelo de Susceptibilidade

Obter o Mapa de Perigosidade (Fig. V) resulta da multiplicação do raster de probabilidade pelo raster de susceptibilidade. Seguidamente, reclassifique esse mapa através do método quantis em 5 classes,

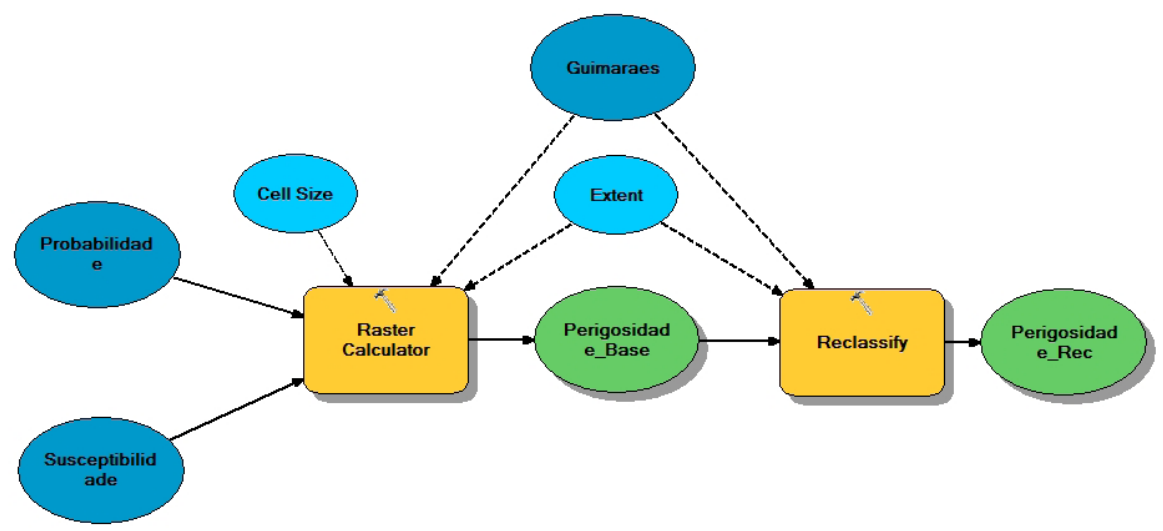

Figura V - Modelação do Mapa de Perigosidade (Modelo de Perigosidade)

No Mapa de Risco de incêndio é necessário utilizar a shapefile do Mapa de Perigosidade anterior não reclassificado. Na tabela da shapefile da COS cria-se o campo "Vulnerabilidade" e o campo "Valor económico" (estes valores estão especificados no Guia técnico do PDMFCI), posteriormente multiplica-se o "Valor económico" pelo campo área da COS (em hectares).Seguidamente, converte-se em raster o valor que resultou da multiplicação anterior, o qual se denomina como "Valor".

Com recurso ao raster calculator efectua-se a multiplicação da "Vulnerabilidade" com o "Valor", obtendo-se assim o "Dano Potencial". Por último, utilizando a ferramenta raster calculator multiplica-se o raster não reclassificado do Mapa de Perigosidade com o raster do 
“Dano Potencial”, elaborando-se o Mapa de risco de incêndio, que deverá ser reclassificado pelo método de Quantis em 5 classes.

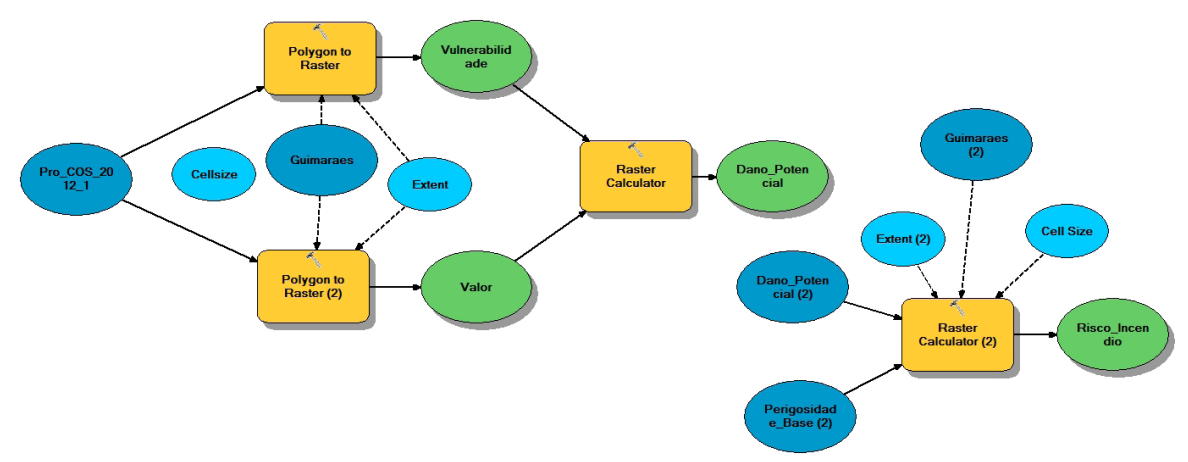

Figura VI - Modelação do Mapa de Risco (Modelo de Risco)

\section{Conclusão}

Os Sistemas de Informação Geográfica são cada vez mais uma ferramenta essencial, e que tornam o trabalho de análise do território mais simplista, pois como salienta Cláudia Costa, 2010, p. 28 «Saber interpretar e correlacionar as características de determinado lugar é de extrema importância para todos aqueles que têm como objecto de estudo o território avaliação da interacção entre indivíduos e o espaço em que ambos se adaptam e modificam ao longo do tempo. Para tal, tem-se recorrido cada vez mais aos Sistemas de Informação Geográfica (SIG)».

Neste sentido, os SIG são ferramenta essencial para os técnicos dos gabinetes de SIG dos municípios. Além disso, o recurso ao Model Builder possibilita que a qualquer momento que seja necessário alterar ponderações ou acrescentar novos dados, isto pode ser feito através do modelo já existente sem necessidade de construir novamente todos o processos.

\section{Bibliografia}

Antunes, Catarina Carvalho, Viegas, Domingos Xavier, \& Mendes, José Manuel. (2011) - Avaliação do Risco de Incêndio Florestal no Concelho de Arganil - Silva Lusitana, 19(2), 165-179. Recuperado em 13 de setembro de 2014, de http://www.scielo.gpeari.mctes.pt/scielo.php?script=sci_arttext\&pid=S0870$63522011000300003 \&$ ing=pt\&tlng=pt. .

Costa, C. (2010) - Localização óptima do futuro Hospital de Sintra, Aplicação de Modelos de LocationAllocation no planeamento de Cuidados de Saúde - Instituto Superior de Estatistica e Gestão da Informação da Universidade de Lisboa.

Direcção da Unidade de Defesa da Floresta (2012) - Plano Municipal de Defesa da Floresta contra Incêndios (PDMFCI) - Guia Técnico. Autoridade Florestal Nacional;

Medeiros, A. (2014) - ArcGis: Criando um Model Buldier - http://andersonmedeiros.com/como-criar-modelbuilder-no-arcgis/ - acedido em 8/09/2014.

Rocha, J.; Torres, R.; Meneses, T. (2013) - Os Solos: Teor de matéria orgânica em solos ardidos e não ardidas na Serra da Penha. Guimarães, Licenciatura em Geografia e Planeamento (Policopiado). 